\title{
Monitoring Land Surface Deformation with Satellite ScanSAR Images: Case Studies on Large Earthquakes in China
}

\author{
Tingchen Jiang, Xiuping Wang, Yuanzhi Zhang and \\ Yu Li
}

Additional information is available at the end of the chapter

http://dx.doi.org/10.5772/intechopen.72834

\begin{abstract}
This chapter presents a new application of scanning interferometric synthetic aperture radar (ScanSAR) interferometry in monitoring land surface deformation caused by large earthquakes. To make better use of the ScanSAR data and obtain a wider deformation observation, this research studied and analyzed certain key elements of ScanSAR interferometry, including coherence, co-registering, methods of removing orbit errors, correction of atmosphere effects, and geoid undulation. The wide swath mode (WSM) is also known as the ScanSAR mode by which synthetic aperture time is shared by adjacent sub-swaths and azimuth resolution that is traded off for a wider coverage. So, it is possible to monitor a larger area of earthquake deformation. In this study, we obtained ScanSAR and Image Mode (IM) data and analyzed coherence, co-registering, methods of removing orbit errors, correction of atmosphere effects, and geoid undulation to monitor land surface deformation caused by large earthquakes in the $405 \times 405 \mathrm{~km}$ field of the Wenchuan earthquake and Yutian earthquake, respectively, in China. The results obtained agree well with that of the investigations of the crustal motion in the study areas.
\end{abstract}

Keywords: deformation monitoring, ScanSAR interferometry, large earthquake

\section{Introduction}

Scanning synthetic aperture radar (ScanSAR) interferometry uses the wide swath synthetic aperture radar (SAR) mode to get geometrical information about the earth's surface [1, 2], 
that is, all of the sub-swaths processed images were obtained to form a wider ScanSAR image. A wider swath can allow for multiple observations of an area in a single orbit cycle. In other words, the region in question can be observed by the sensors in several different orbit tracks [3-5]. Although resolution of the ScanSAR mode is relatively low, its many merits such as wider swaths and short intervals [6] for the deformation of a large area can contribute to effective imaging.

The ScanSAR concept was first introduced in the 1980s and the ScanSAR mode of Radarsat satellite was designed in 1988. Burst mode radar was first applied to the Magellan mission to map the Venus surface in order to reduce data volume and allow the use of other instruments in between radar bursts $[5,7,8]$. To our knowledge, the first ScanSAR amplitude image of the Earth was in 1996 [9]. The first ScanSAR interferogram was obtained by using ScanSAR data of Radarsat satellite in 1999 [10]. The ScanSAR mode was initially used on the National Aeronautics and Space Administration (NASA) Spaceborne Imaging Radar C-band (SIRC) mission in 1994 [7, 10]. Many SAR sensors such as Envisat, Radarsat-2, Advanced Land Observing Satellite (ALOS), COSMO-SkyMed, and TerraSAR-X are capable of imaging in the ScanSAR mode. On Envisat, the ScanSAR mode was called as Wide Swath Mode (WSM) and has five sub-swaths. Unfortunately, communication with Envisat was lost on April 8, 2012 and, consequently, the mission officially ended on May 9, 2012. The Sentinel-1A satellite was launched in April 2014 and can operate the satellite SAR sensor that is capable of imaging in the ScanSAR mode. The ScanSAR mode is called as Interferometric Wide-swath mode (IW).

With many of the current SAR satellites carrying advanced imaging capabilities, ScanSAR mode acquisitions are replacing the conventional strip-map mode acquisitions for portions of a SAR mission [11]. In light of future SAR missions and modifications of existing SAR mission imaging strategies, a detailed study of ScanSAR interferometry for ground motion monitoring of large earthquakes will provide significant input for mission planning and InSAR applications [6].

To use ScanSAR data for deformation monitoring, same as Image Mode (IM) data, many studies have been focused on the following three points: (1) imaging algorithms [12-15]; (2) removing coherence of spaceborne ScanSAR interferometry [3-5]; and (3) developing new algorithms of ScanSAR interferometry $[12,13]$.

With regard to ScanSAR interferometry, scholars have studied how to form the interference $[4-6,12,13]$, but the effects of errors are yet to be studied systematically. For example, ScanSAR interferometry was applied in Wenchuan earthquake [16, 17]; however, in the study of monitoring the surface deformation, they only considered the influence of the atmosphere on the results using Medium Resolution Imaging Spectrometer (MERIS) data. In fact, to obtain a high accuracy ScanSAR interferogram, some key techniques such as geoid undulation, correction of atmosphere effects, and reducing orbit error besides removing coherence and mosaicking of wide swath SAR data were studied. In this chapter, we applied these key techniques to the wider deformation fields of ENVISAT ScanSAR images to monitor the land deformation caused by large earthquakes such as Wenchuan (2008) and Yutian (2008), respectively, in China. 


\section{Settings and data processing}

The ScanSAR mode is able to image multiple strips of land called sub-swaths from a single satellite pass. This can be achieved by electronically steering the radar beam through a set of elevation or look angles. Each sub-swath is collected in the burst mode, wherein the interburst gap time corresponds to the time when the sensor is imaging the remaining sub-swaths [5]. The raw data from each sub-swath are processed to burst mode images and merged into a composite ScanSAR image. In the ScanSAR mode, the satellite electronically steers the beam between sub-swaths, while in the strip-map mode, the beam is maintained within a single sub-swath. The elevation angle is often cycled enough during ScanSAR operation to maintain contiguous ground coverage. The process of ScanSAR interferometry is shown in Figure 1, which includes mosaicking bursts, image co-registration, common band filtering, and so on. In addition to mosaicking bursts to sub Single Look Complex (SLC) and sub-interferograms, the other is the same as the IM interferometry.

The principle of ScanSAR interferometry in the burst is the same as that of IM $[5,6,12,13]$. If the SAR satellite at certain time intervals orbits (typically tens to $100 \mathrm{~m}$ ) and scans on a region repeatedly, the spatial positions are S1 and S2, respectively, during the two different flight processes. The spatial interferometric baseline vector is B and named baseline length. The

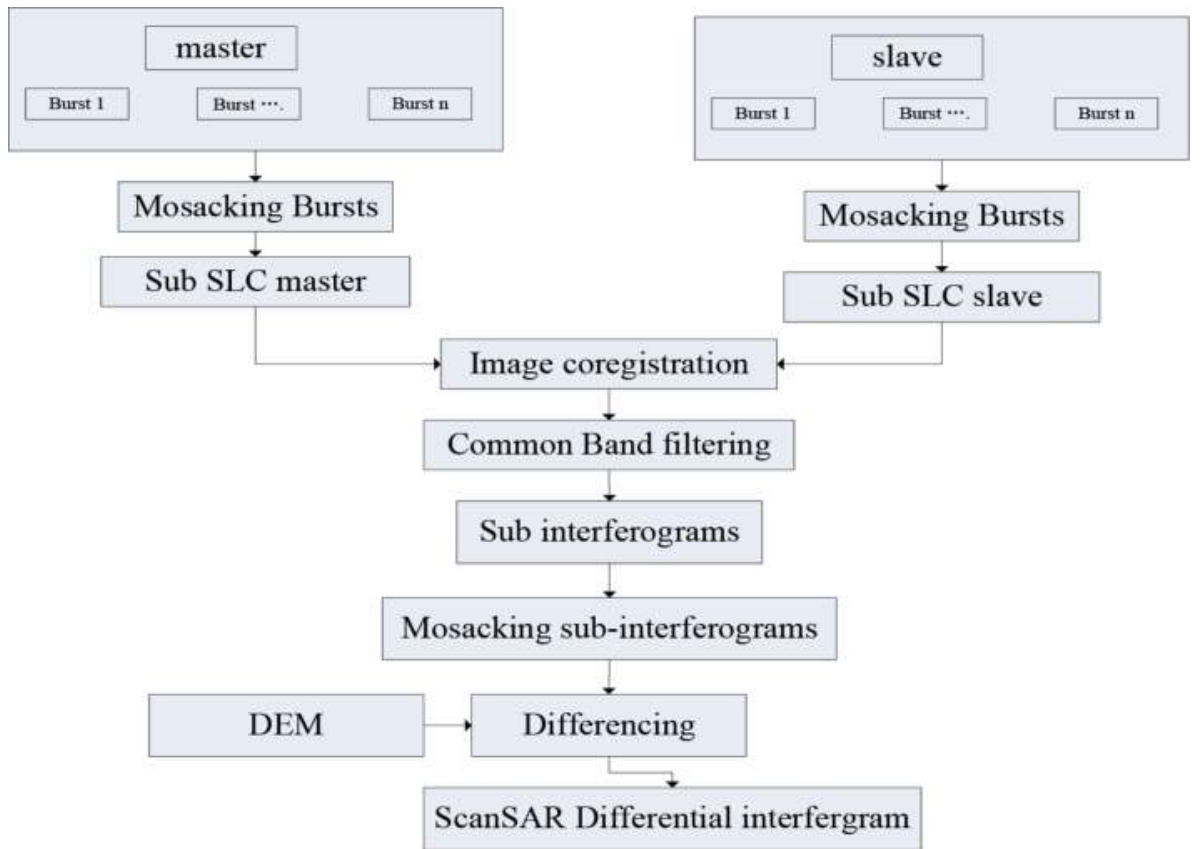

Figure 1. The data processing of ScanSAR interferometry. 
angle between the baseline vector $\mathrm{B}$ and horizontal vector is baseline obliquity, and $\theta$ is the incident angle. In addition, two spatial positions, $\mathrm{S} 1$ and $\mathrm{S} 2$ to ground point $\mathrm{P}$ are $\mathrm{r}$ and $\mathrm{r}+\Delta r$. At the same time, the interferometric baseline is divided into a parallel baseline component $B_{\|}\left(B_{\|}=B \sin (\theta-a)\right.$ which is parallel to the line-of-sight direction and vertical baseline component $B_{\perp}\left(B_{\perp}=B \cos (\theta-a)\right.$ (perpendicular to the view direction). According to the principle of conventional Differential Interferometric Synthetic Aperture Radar (DInSAR), the interferometric phase of the ScanSAR interferogram can be expressed as:

$$
\phi=\frac{4 \pi}{\lambda}\left(B_{\|}+\frac{B_{\perp}}{r \sin \theta} h-\Delta p\right)
$$

where $\phi$ is the total phase after unwrapping and $\Delta p$ is surface deformation of the line of sight. If surface deformation is obtained using two pass methods, surface deformation of the line of sight, $i$, can be written as:

$$
\Delta p=B_{\|}+\frac{B_{\perp}}{r \sin \theta} h-\frac{\lambda}{4 \pi} \phi
$$

From Eq. (2), it can be seen that surface deformation of the line of sight is closely related to the ground phase $\frac{4 \pi}{\lambda} B_{1}$ and Digital Elevation Model (DEM)error. If Eq. (2) is transformed as the derivation of $\mathrm{B}, \mathrm{h}$, and $\mathrm{a}$, the results are as follows:

$$
\begin{aligned}
& \frac{d \Delta p}{d B}=\sin (\theta-a)+\frac{B_{\perp} h}{r \sin \theta} \\
& \frac{d \Delta p}{d a}=-B \cos (\theta-a)+\frac{B \sin (\theta-a)}{r \sin \theta}-\frac{B \cos (\theta-a) \cos \theta}{r \sin ^{2} \theta} \\
& \frac{d \Delta p}{d h}=\frac{B_{\perp}}{r \sin \theta}
\end{aligned}
$$

That is,

$$
\begin{aligned}
\sigma_{\Delta p} & =\left(\sin (\theta-a)+\frac{B_{\perp} h}{r \sin \theta}\right) \sigma_{B} \\
\sigma_{\Delta p} & =\left(-B \cos (\theta-a)+\frac{B \sin (\theta-a)}{r \sin \theta}-\frac{B \cos (\theta-a) \cos \theta}{r \sin ^{2} \theta}\right) \sigma_{a} \\
\sigma_{\Delta p} & =\frac{B_{\perp}}{r \sin \theta} \sigma_{h}
\end{aligned}
$$

where $\sigma_{B}$ is the error of baseline, $\sigma_{a}$ is the error of baseline obliquity, and $\sigma_{h}$ is DEM error. According to the abovementioned equation, regardless of baseline length error, baseline obliquity errors will affect the results of ScanSAR interferometry, and the influence degree is related to the slant range. However, DEM error is related to both the oblique distance, angle of incidence, and the vertical baseline length. In addition to these errors, the atmospheric refraction phase is also an influencing factor. Undoubtedly, in order to obtain deformation data of 
large earthquakes with ScanSAR interferometry, the following techniques and methods were applied to eliminate these errors in the monitoring of land deformation.

\subsection{Removing influence of geoid difference}

In order to obtain deformation data of the region in question through DInSAR, it is necessary to use two or more scenes of SAR data to form a differential interferogram. Since the SAR data are not sufficient and an outlay of the research project is not relatively scarce, there is only one way to use DEM to get a differential interferogram. Currently, DEM such as Shuttle Radar Topography Mission (SRTM) and Advanced Spaceborne Thermal Emission and Reflection Radiometer Global Digital Elevation Model (ASTER GDEM) are referenced to the Earth Gravitational Model 1996 (EGM96) geoid datum, while in interferometry SAR (InSAR), data processing is established on the ellipsoidal height (e.g., WGS84); therefore, both data are inconsistent.

In this study, geodetic height was obtained based on the EGM96 gravity field model. To convert EGM96 height into geodetic height, geoid gap $\mathrm{N}$ can be calculated using the following formula [18]:

$$
N(\theta, \lambda)=\varsigma_{Z}+\frac{G M}{r_{p} \gamma_{p}} \sum_{n=2}^{N} C_{n m} Y_{n m}(\theta, \lambda)+\frac{\Delta g_{B}(\theta, \lambda)}{\bar{\gamma}} H(\theta, \lambda)
$$

According to Eq. (5), the elevation of SRTM or GDEM data is converted into geodetic height.

\subsection{Correction of atmosphere effects}

Atmospheric refraction is an important source of error for interferometric synthetic aperture radar, the reason is that the radar signal propagation in atmosphere by tropospheric and ionospheric refraction is delayed, or it gets ahead of its phase. With other similar mode interference, atmospheric effects with other errors (such as DEM and baseline error) also seriously affect the final deformation monitoring results for ScanSAR interferometry; however, unlike other laws of error influence, atmospheric effects are not affected by radar imaging geometry but are only related to the atmospheric relative states of the two ground observations. The ionosphere at about $60-2000 \mathrm{~km}$ height has inhomogeneous bodies from several kilometers to hundreds of thousands of meters. SAR satellites are inclined cone when exposed to the ground; at the same time, the scanning area of the ground is less than a few hundred kilometers, so it has less influence. In general, it is basically eliminated by the difference in the spatial domain. Tropospheric delay can be divided into two parts, the dry and wet delay. Dry delay is generated by no water vapor atmospheric delay and accounts for about $90 \%$ of the total delay, and the model accuracy can reach submillimeter range. In addition, the time domain is relatively stable and has the characteristics of large-scale changes in the airspace, while dry delay is negligible after double difference. The wet delay is caused by the water vapor in the atmosphere, which accounts for about $10 \%$ of the total delay. However, it is difficult to establish a real-time and accurate model due to the uneven distribution of water vapor in the atmosphere and the rapid change. Therefore, the main error of troposphere delay is caused by wet delay. 
In order to reduce or remove the wet delay of ScanSAR interferometry $[5,6,12,13]$, the atmospheric effects of corrections were analyzed based on medium-resolution imaging spectrometer (MERIS) data. When compared with the correction method of atmospheric effects using external data such as Moderate Resolution Imaging Spectroradiometer (MODIS), making use of MERIS, correct atmospheric effects of advanced synthetic aperture radar (ASAR) interferogram have great superiority, for the imaging time of ASAR and MERIS are synchronous, and the resolution of ScanSAR is close to the resolution of MERIS data.

The reason of correction of atmospheric effects based on MERIS data is that atmosphere delay information is first obtained using two MERIS data corresponding to two SAR data to be converted into path delay by using function mode. In the end, this path delay will be removed so that atmospheric effects in the ScanSAR interferogram is corrected. The process of correcting atmospheric effects is shown in Figure 2. When using MERIS data to correct atmosphere effects, it involves removing cloud, difference, and co-registration. As the water vapor algorithm of MERIS is very sensitive to the cloud, it is necessary to use Cloud product categories to obtain cloud pollution and then to interpolate relevant data. To reduce interpolation errors, MERIS data will only be calibrated without the removal of the mask method.

\subsection{Reducing orbit error}

Orbit error is another key factor in ScanSAR interferometry because it influences baseline estimation precision. Baseline estimation is required for a number of operations, including

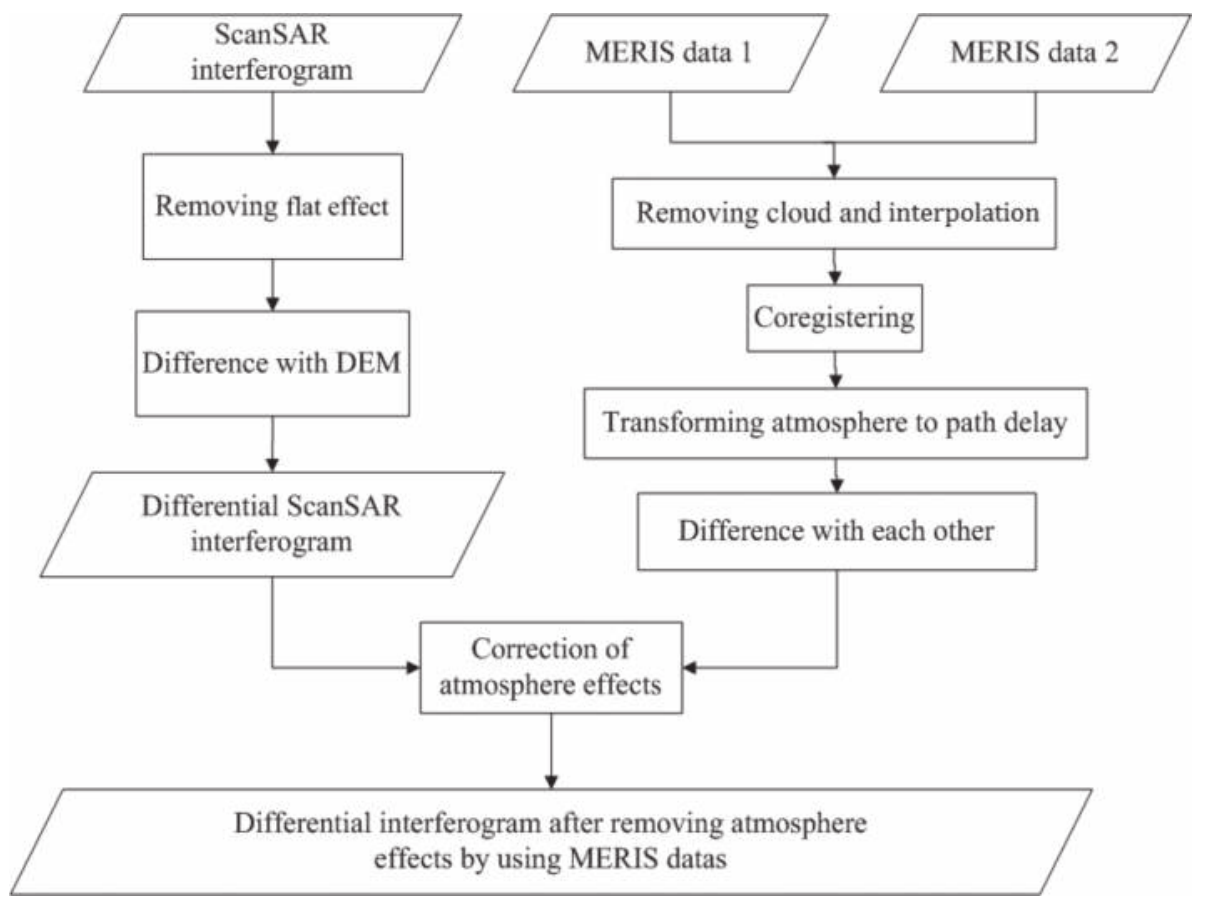

Figure 2. The process of basic idea of the correction of atmospheric effects using MERIS data. 
common band filtering, flattening of the interferogram, phase unwrapping, and derivation of interferometric heights from the unwrapped phase $[5,6]$.

The baseline can be estimated using (1) orbital information, (2) fringe rate of the interferogram, and (3) ground control points (after unwrapping). It is clear that the method based on state vectors works well when accurate state vectors are available. In the absence of reliable state vector information, the local fringe rate at the center of the interferogram can be used to obtain an estimated perpendicular baseline. The third method is the most effective because its coverage is very wide and the fringe rate is not always constant. Moreover, the size and influence of the baseline error can be seen more clearly in the ScanSAR interferogram.

\section{Case study: Wenchuan earthquake}

\subsection{Background}

Wenchuan earthquake struck on May 12, 2008 with M8.0 of the high strength of a large earthquake, which resulted in a large number of collapsed houses, about 80,000 casualties, tens of thousands of geological hazards, such as landslide and collapse, and debris flow. The earthquake led to a large number of rupture and regional ground deformation on the surface, including the gaining of much of the information of the earth's dynamics [16, 19] (Figure 3).

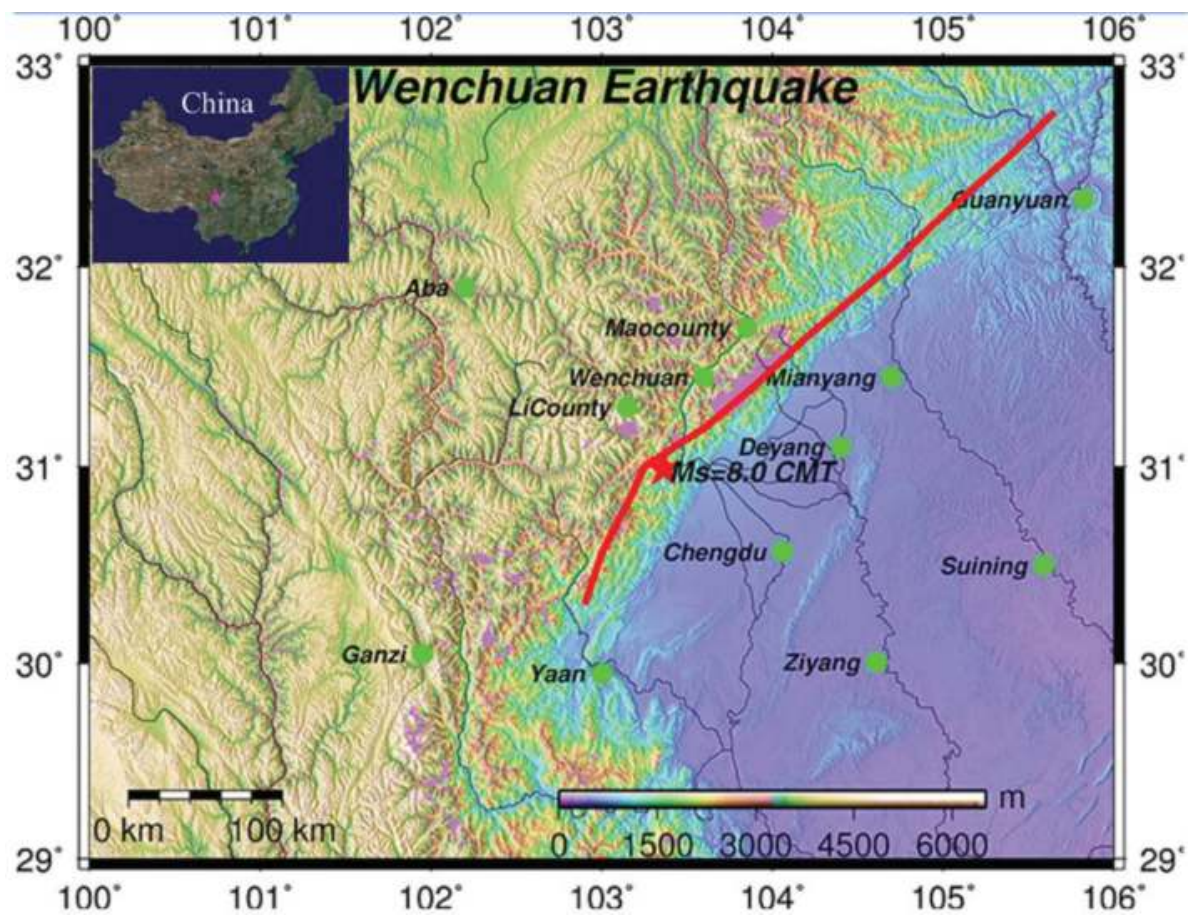

Figure 3. Location of Wenchuan earthquake ( $\star$ is center of Wenchuan earthquake). 
After the Wenchuan earthquake, many studies were conducted to simulate the seismogenic structure and seismic characteristics [16, 19-22], such as tectonic activities, intensity, and focal mechanism, by which the research methods including field survey, gravity survey, GPS, and the conventional interferometric SAR were applied, and there were some valuable achievements [19-22]. However, since the approaches applied have their own limitations and shortcomings (i.e., low precision, large discreteness, narrow scopes, influences of natural factors, etc.), results on the fracture zone length, direction of rupture, and rupture surface size for Wenchuan earthquake are different [23-25]. The co-seismic deformation field of the Wenchuan earthquake by ScanSAR interferometry was studied because of the defects of the abovementioned methods [17]. However, there were a lot of errors which had not been removed and considered in the processing of interferometry such as geoid undulation and orbit error. In addition, when atmospheric effects had been considered for removal, Moderate Resolution Imaging Spectroradiometer (MODIS) data was only used to reduce the influence of atmosphere. In fact, MERIS is better than MODIS because the MERIS and ScanSAR data used were derived from the ENVIronmental SATellite (ENVISAT) satellite, so as to maintain synchronization. Therefore, these factors were considered in this chapter.

\subsection{Data and processing}

The Wenchuan earthquake was so strong and its rupture zone was about $300 \mathrm{~km}$. In order to mantle the overall earthquake deformation field, two scenes of ENVISAT ScanSAR data were selected to cover the deformation field, with the imaging times of January 25, 2008 (before the earthquake) and June 13, 2008 (after earthquake), respectively.

Before interferometry processing, the geoid difference of the GDEM of Wenchuan was computed based on EGM96. The regional level of the contour line is presented in Figure 4, from which the maximum and minimum value of the regional level is -28.78 and $-42.98 \mathrm{~m}$, respectively, with a difference of $14.2 \mathrm{~m}$.

The deformation zone of Wenchuan earthquake is located in the Western Sichuan province. In addition, the imaging time of both ASAR image and MERIS vapor products were consistent with the similar spatial resolution of both ScanSAR interferogram and MERIS, so that the atmospheric effects can be reduced using MERIS data. Figure 5 shows the result that is absolute wet delay of January 25, 2008 (Figure 5a) and June 23, 2008 (Figure 5b) in the Wenchuan earthquake area. Figure 6 shows the corresponding relative atmospheric wet delay after difference. As shown in Figure 5, the weather of two periods were in good condition, and the regional atmospheric wet delays of the two periods were about $3 \mathrm{~mm}$. Therefore, it is necessary for the ScanSAR differential interferogram to correct atmosphere effects based on the relative wet delay.

Image co-registration of ScanSAR with the same IM mode can determine the final result quality. In order to form a robust and reliable interferogram and to make the co-registration precision to remain less than 0.2-pixel, it is applied with the co-registration method based on DORIS precise orbit and the external DEM. After co-registration and differential interferometry, it is possible to obtain the sub-swath interferogram and sub-swath interferograms are mosaicked to the total ScanSAR interferogram. At the end, flat and topographic phases are removed from 
the interferogram to obtain the differential interferogram as shown in Figure $7 \mathbf{a}$ and $\mathbf{b}$ after phase unwrapping which is the result where the baseline is mended using the ground control point (GCP) method.

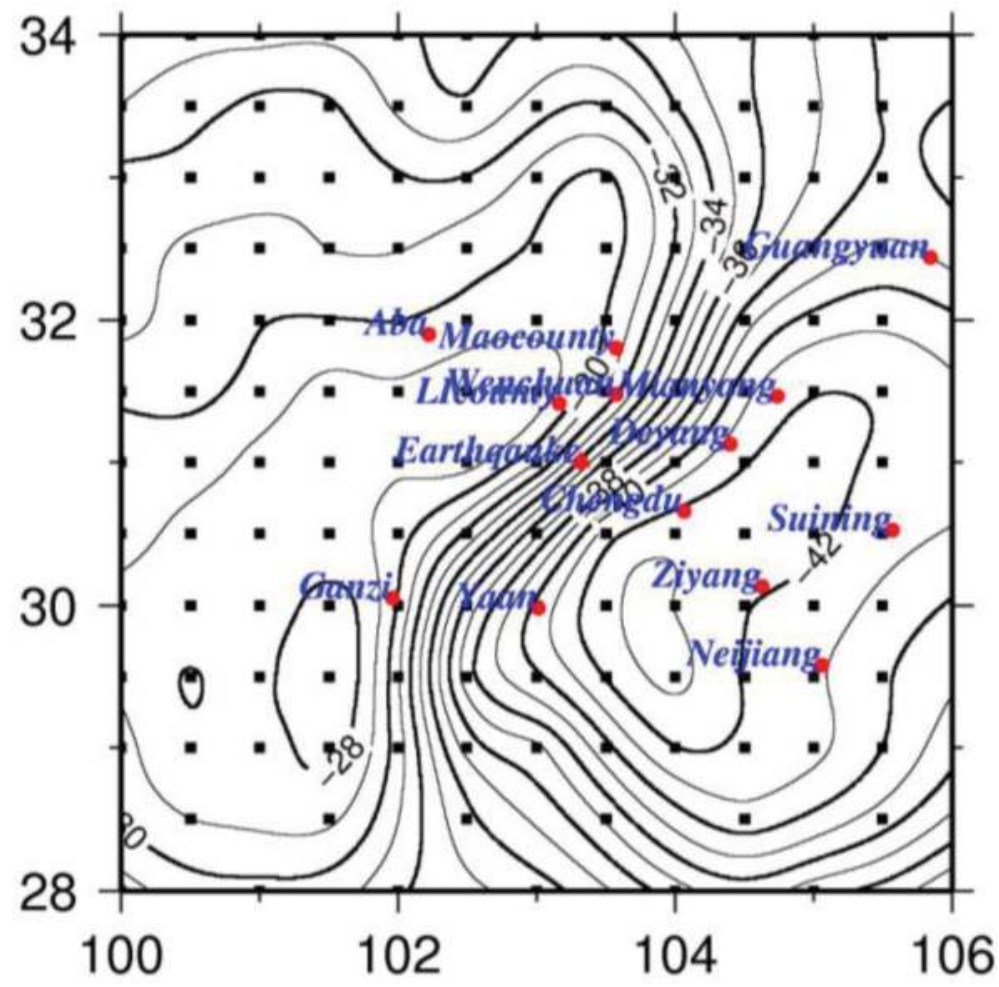

Figure 4. Wenchuan regional level of contour lines.

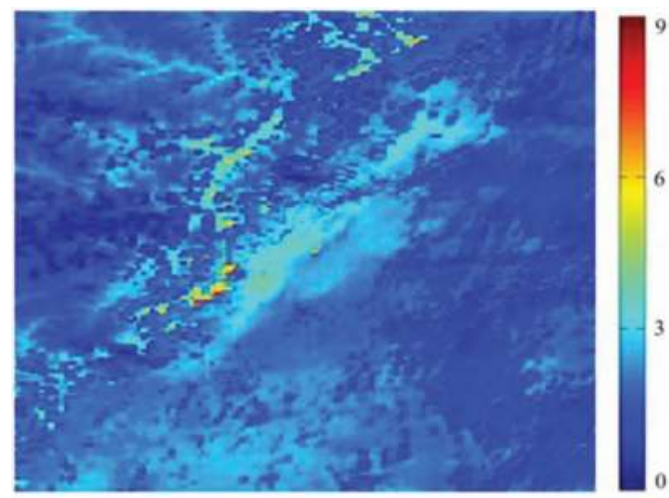

(a)

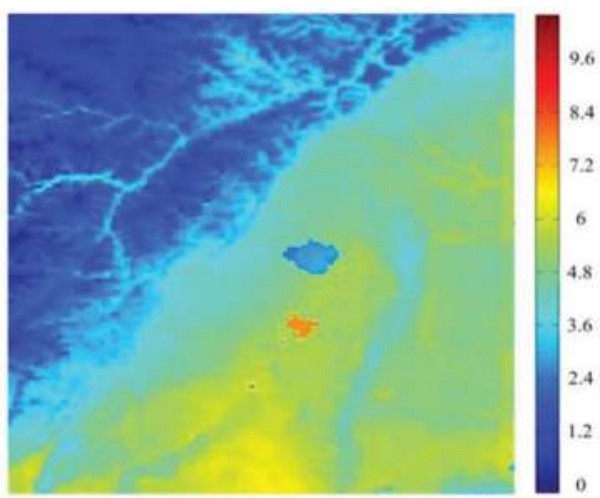

(b)

Figure 5. Wenchuan area of absolute wet delay of January 25, 2008 (a) and June 23, 2008 (b) (unit mm). 


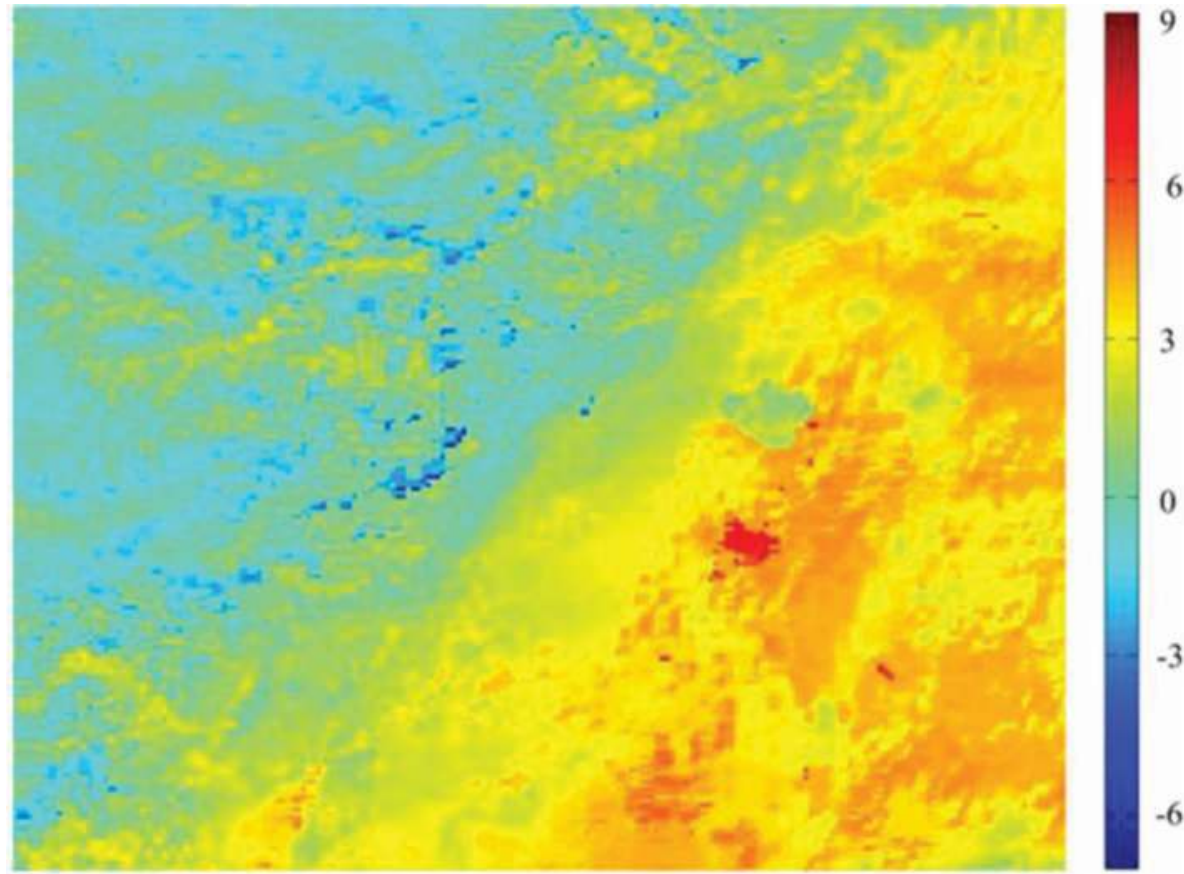

Figure 6. Relative atmospheric wet delay after difference (unit $\mathrm{mm}$ ).

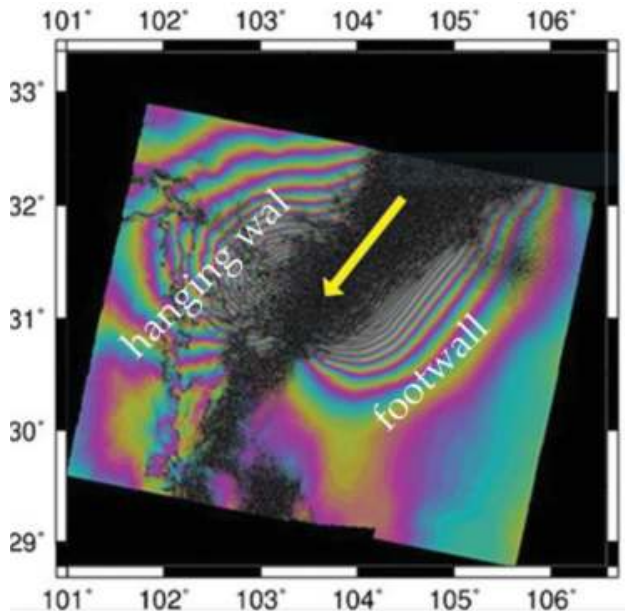

(a)

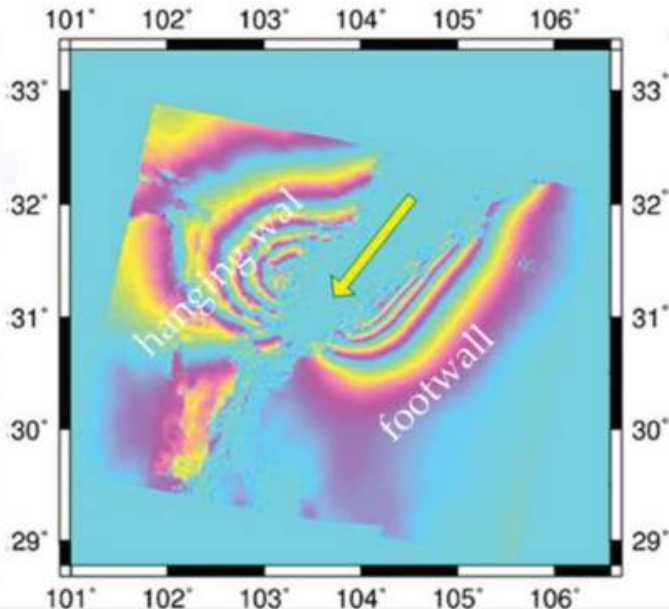

(b)

Figure 7. Differential interferogram of Wenchuan earthquake. (a) before phase unwrapping (b) after phase unwrapping. 


\subsection{Results and discussions}

Figure 7 shows that the size of the whole area that the ScanSAR interferogram covered is about $405 \times 405 \mathrm{~km}$, which is sufficient to reflect the total seismic deformation field and seismogenic fault location of the Wenchuan earthquake. The deformation region can be roughly divided into three areas, while the middle one is a noncoherent region where the Wenchuan seismic belt is located. The noncoherent field results from the fact that the deformation gradient in the region exceeds the C-band monitoring ability of ASAR images. This means that if the deformation of two adjacent pixels exceeds $\pi$ radian, the coherence is pure noise. Consequently, landslides and the destruction of vegetation investigated in the field caused by the earthquake led to the loss of coherence. The other two regions of the interference fringes with increasing distance away from the fault and is more and more sparse, but the right side of the noncoherent area is the footwall (i.e., Chengdu Plain), while the wrapped phase image shows nearly parallel extension. On the other side of the noncoherent zone is the hanging wall of fault which is the concentric circular interference fringe area.

According to the phase in Figure 7, considering relative atmospheric wet delay in Figure 6 and its space imaging geometric relationship, ScanSAR interferometry value is transformed into the deformation of line of sight (LOS) as shown in Figure 8. To further analyze deformation, as

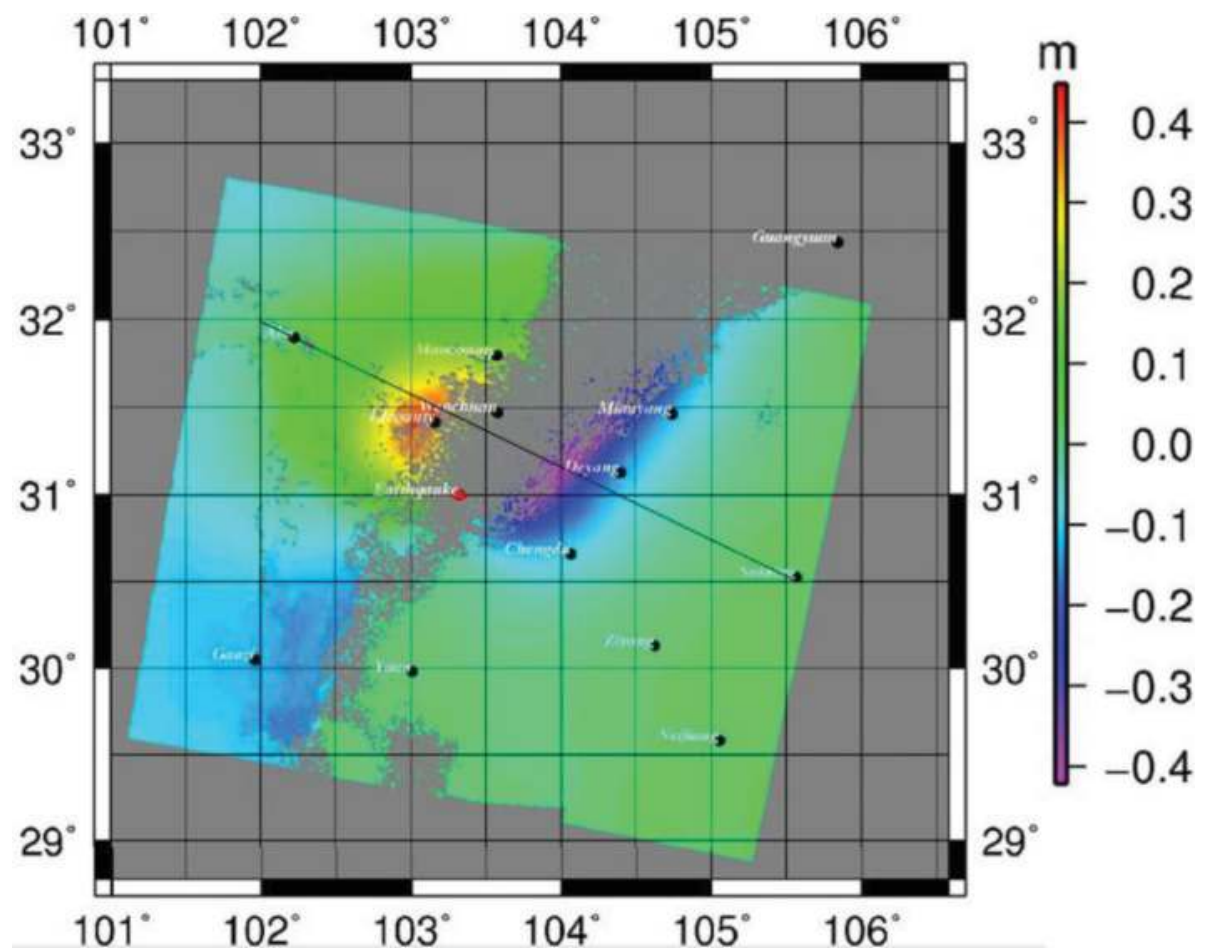

Figure 8. Wenchuan earthquake deformation field by ScanSAR interferometry. 


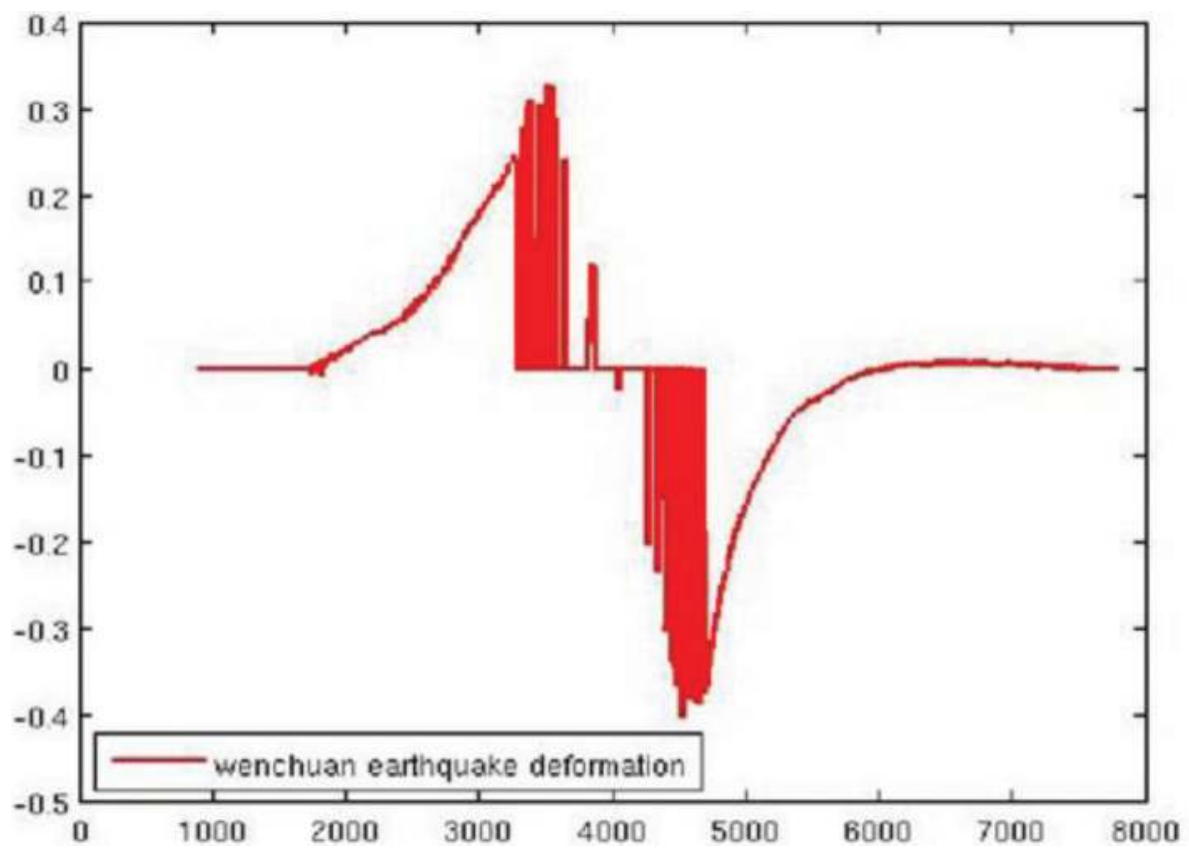

Figure 9. Deformation profile of Wenchuan earthquake along the black line in Figure 8 (unit: M).

the center of interferogram is a noncoherent district, the interferogram is unwrapped, respectively, at different points of the upper west and lower east image as the reference point, so that it is possible to gain two deformation results. Figure 8 is the deformation field taken at the lower east corner as reference point, which shows that the deformation scope of the Wenchuan earthquake is very great, even the A'ba region recorded deformation. In addition, deformation of the Chengdu region is about $0.10 \mathrm{~m}$. To analyze the deformation, its profile is mapped as shown in Figure 9. Based on profile of the two points, the max deformation value of the left part of the fault is $0.48 \mathrm{~m}$, while that of the right part is $-0.42 \mathrm{~m}$. When compared with the west part, the deformation scope of the east part is narrow, while the deformation grades are very high, especially near the fault.

\section{Case study: Yutian earthquake}

\subsection{Background}

There was an M7.3 earthquake at the boundary of Yutian County in Hotan Prefecture, Xinjiang, China, on March 21, 2008, and the epicenter of earthquake (Latitude: 35.6, Longitude: 81.6) was $225 \mathrm{~km}$ from the Hetian city and about $120 \mathrm{~km}$ from the Yutian county, as presented in Figure 10. Yutian earthquake was considerably destructive. This is again an earthquake higher than M7.0 in the western edge of the Qinghai Tibet Block that occurred after Kunlun 


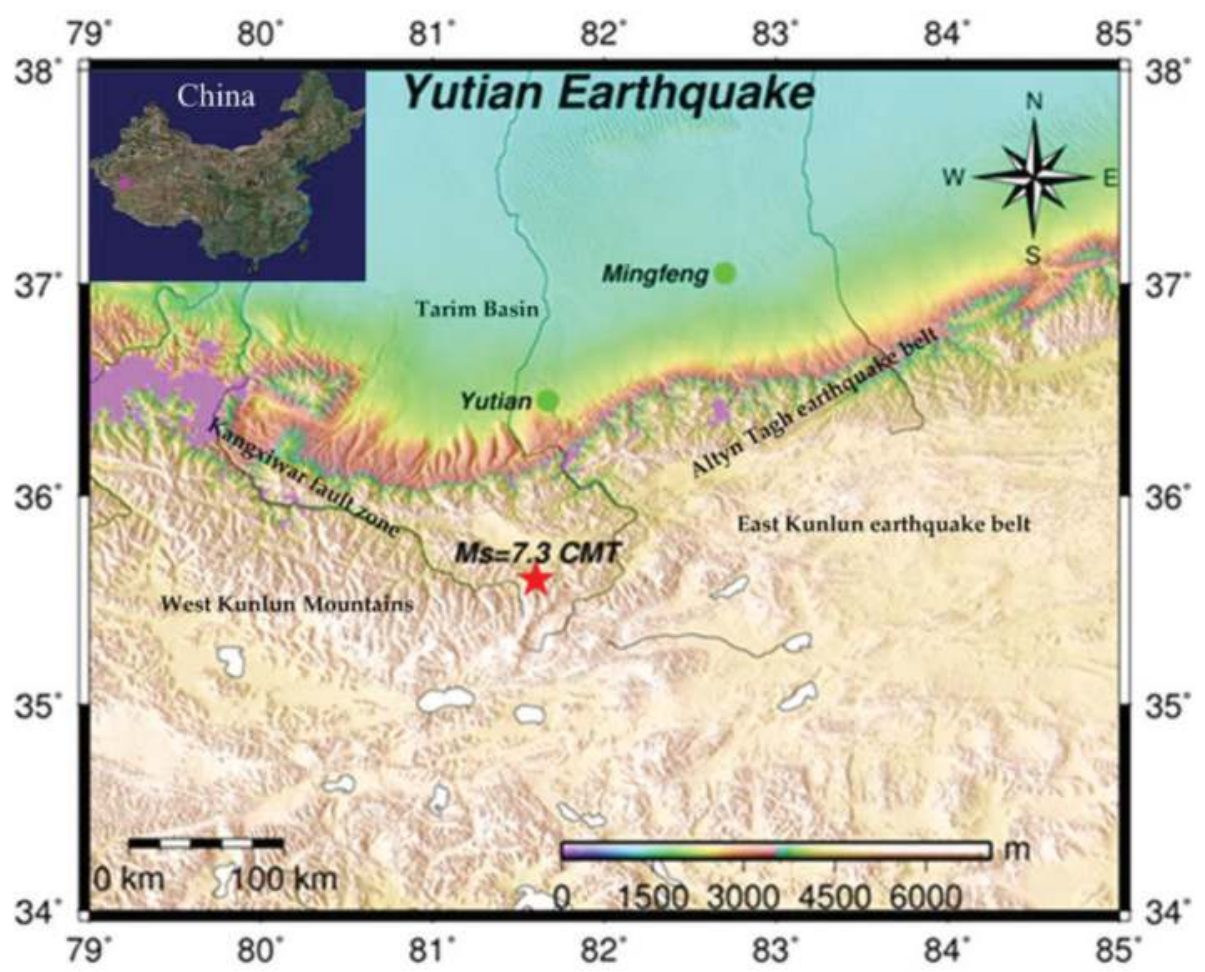

Figure 10. Location of Yutian earthquake ( $\star$ is center of Wenchuan earthquake).

Mountain earthquake of magnitude 8.1 in 2001, and a M6.2 earthquake was in this region in 2012. According to statistics, there were 33 above M3.0 earthquakes in this region from January 2012 to November 2013. Thus, this is an earthquake-prone area and as a research hotspot [26].

Yutian earthquake occurred in the intersection of the East Kunlun earthquake belt, Kangxiwar fault zone and Altyn Tagh earthquake belt, which is near the edge of the West Kunlun Mountains, located in the southern part of Tarim Basin, belonging to Tibet and two big western active plots. Although the Yutian earthquake in the basin limits the distribution range of aftershocks, the earthquake deformation range still reflects the motion state of the active block [26]. The activities of Arkin fracture zone are the main causes of the Yutian earthquake. Strong earthquake activities of Arkin fault are often accompanied by earthquake activity in the Qinghai Tibet Plateau and its surrounding main fault zone. For example, Wenchuan M8.0 earthquake took place more than 1 month after the Yutian earthquake, and 2 years later, the M7.1 Yushu earthquake occurred.

\subsection{Data and processing}

To monitor the total deformation field of Yutian earthquake, ASAR data of ScanSAR and two IM models of the ESA ENVISAT satellite were selected to study seismic deformation as shown 
in Table 1. Using Global Digital Elevation Model (GDEM) to get differential interferogram and the geoid difference of the GDEM of Yutian was computed based on EGM96. The regional level of the contour line is shown in Figure 11, in which the maximum and minimum value of the regional level is 62.3 and $-19.8 \mathrm{~m}$, respectively, and the difference between them is $42.5 \mathrm{~m}$.

After co-registering and differential interferometry, sub-swath interferogram was acquired and then sub-swath interferograms were mosaicked to the total ScanSAR interferogram. At the end, the flat and topographic phase were removed from the interferogram to obtain a differential interferogram as seen in Figure 12a, while Figure 12b is the differential interferogram obtained after phase unwrapping, and its perpendicular baseline is $75.6 \mathrm{~m}$, in both cases the data of November 29, 2007 and April 17, 2008 were applied.

\subsection{Results and discussions}

As shown in Figure 12, the ScanSAR differential interferogram mantle scope is about $405 \times 405 \mathrm{~km}$, almost reflecting the deformation field and fault place of the Yutian earthquake. At the same time, it also shows that the surface deformation influence on the scope of Yutian earthquake was enormous. In addition, the earthquake isoseismal is oval, and the differential interferogram is roughly divided into two areas, namely, the coherent and noncoherent regions. Yutian earthquake center is located in the noncoherent region (shown in Figure 12).

The noncoherent area on the left is the hanging wall of the earthquake, while the right side is the footwall of the earthquake. Moreover, interference fringes in these regions with increasing distance away from the fault are more and more sparse, but when compared with the hanging wall of the earthquake, footwall deformation decays earlier.

As shown on the upper right corner area in Figure 12b, even far away from the fault, the case still remained strips. To verify whether the interference fringes is caused by the seismic deformation, another four landscape ScanSAR data before and after the earthquake were processed and the results are shown in Figure 13. Figure 13a is the interferometry result using two data of pre-earthquake and Figure 13a shows the interferometry result using two data between pre-earthquake and post-earthquake.

\begin{tabular}{llllll}
\hline $\begin{array}{l}\text { Track } \\
\text { number }\end{array}$ & $\begin{array}{l}\text { Imaging time } \\
\text { (YY-MM-DD) }\end{array}$ & $\begin{array}{l}\text { Ascending or } \\
\text { Descending }\end{array}$ & $\begin{array}{l}\text { Imaging } \\
\text { mode }\end{array}$ & $\begin{array}{l}\text { Polarization } \\
\text { mode }\end{array}$ & Orbit number \\
\hline 434 & $2007-05-03$ & Descending & WSS & HH & 30,862 \\
& $2007-06-07$ & Descending & WSS & HH & 31,363 \\
& $2007-2011-29$ & Descending & WSS & HH & 28,085 \\
& $2008-04-17$ & Descending & WSS & HH & 33,095 \\
& $2008-05-22$ & Descending & WSS & HH & 33,196 \\
477 & $2008-04-20$ & Descending & IM & HH & 33,093 \\
& $2008-04-01$ & Descending & IM & HH & 33,083 \\
\hline
\end{tabular}

Table 1. SAR data to obtain deformation of Yutian earthquake. 


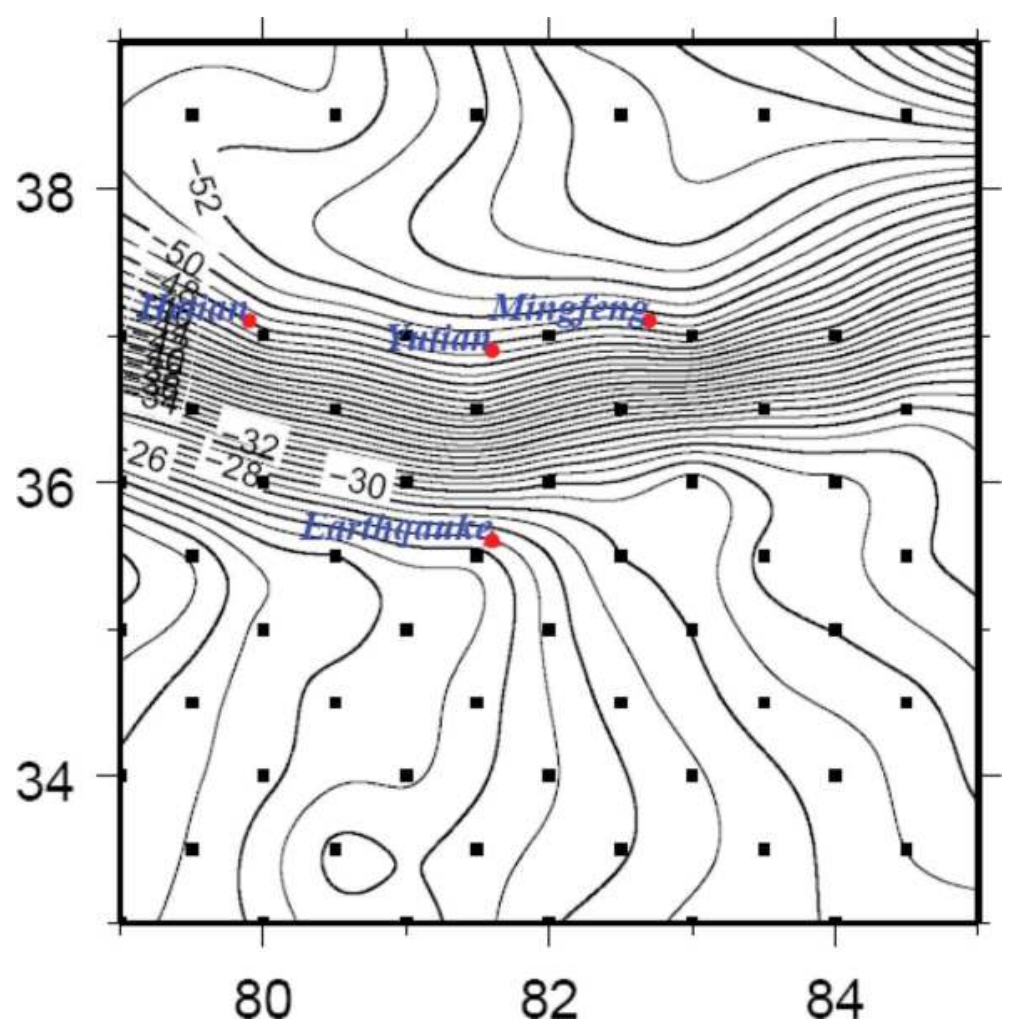

Figure 11. Geoid isolines of Yutian region.

From Figure 13a, it is clear that the upper right corner areas of the interferogram remain as interference fringes even when the vertical baseline is $2.87 \mathrm{~m}$; however, Figure $\mathbf{1 3} \mathbf{b}$ has no interference fringes. Undoubtedly, this proved that these stripes are not caused by a DEM error or other factors but Yutian earthquake. Although the region from the earthquake center is about $170 \mathrm{~km}$ and located in east Kunlun and Arkin faults, it is found that transition part between the region and earthquake deformation field has no interference fringes, which may be related to the Bayan Kara block geological structure.

Based on the spatial geometry and differential interferogram, ScanSAR interferometry observations are transformed into the deformation value of the line of sight. As shown in Figure 14, the rupture strip of Yutian earthquake is about $80 \mathrm{~km}$. The maximum deformation of hanging wall for the fault is $0.41 \mathrm{~m}$ and the maximum of the footwall deformation value is $0.32 \mathrm{~m}$. When compared with the footwall, the hanging wall deformation range is narrow, but the deformation gradient near the fault is great. In addition, ASAR image mode data are used to form the interferometry and deformation results as shown in Figure 15. It is clear that the differential interferometry results of the image mode reflect almost fault and deformation distribution of the Yutian earthquake. The maximum deformation of the hanging wall is $0.60 \mathrm{~m}$ 
and the maximum deformation of the footwall is $0.63 \mathrm{~m}$. The noncoherent region of the IM interferometry is in a certain range in comparison with results from the ScanSAR mode interference. Furthermore, the non-coherent region is small and the deformation results reflected is not the same, which is mainly due to the higher resolution induced by IM.

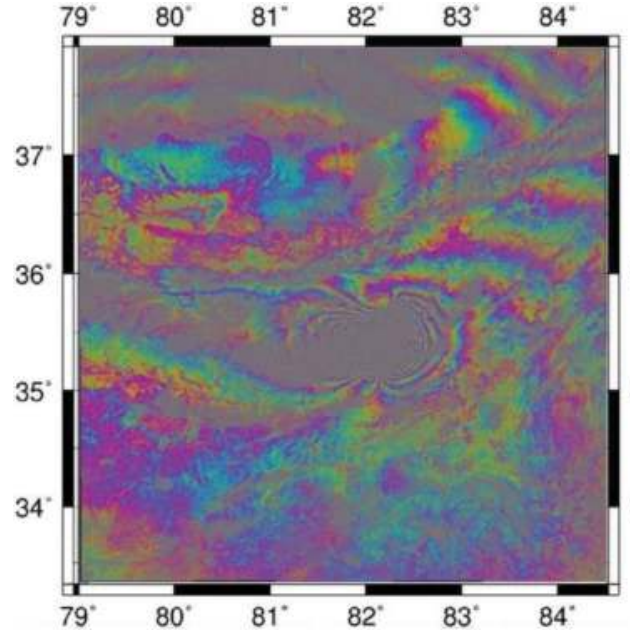

(a)

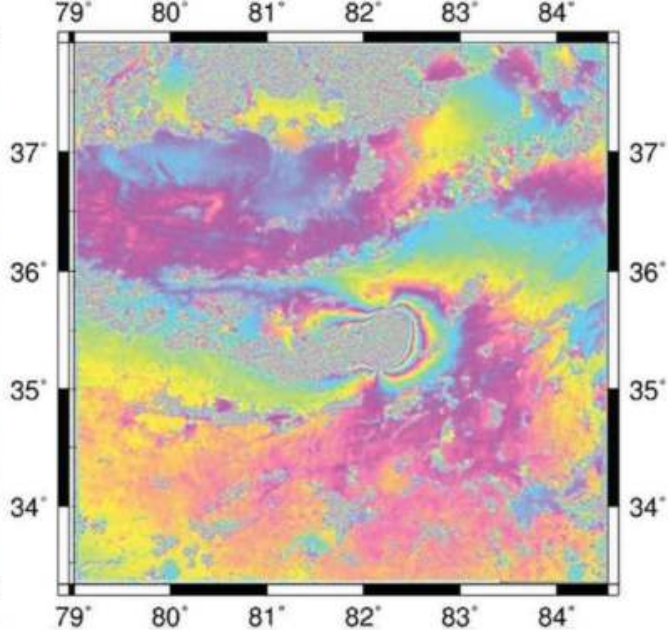

(b)

Figure 12. Differential interferogram of Yutian earthquake. (a) wrapped interferometric phase and (b) unwrapped interferometric phase.

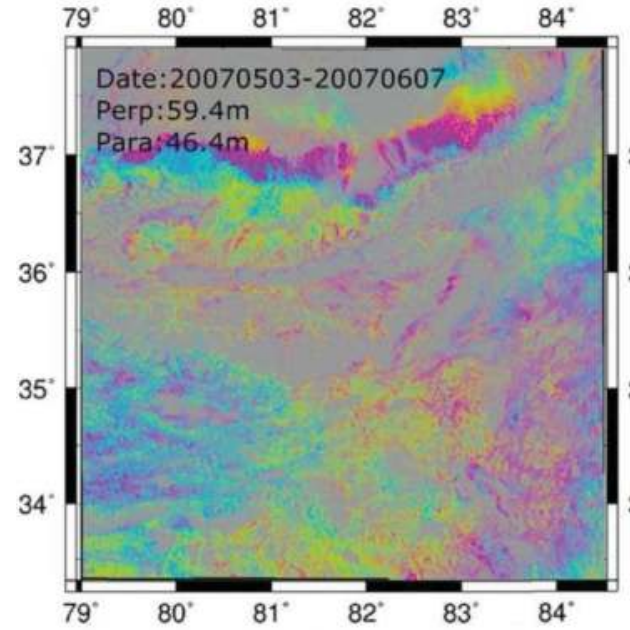

(a)

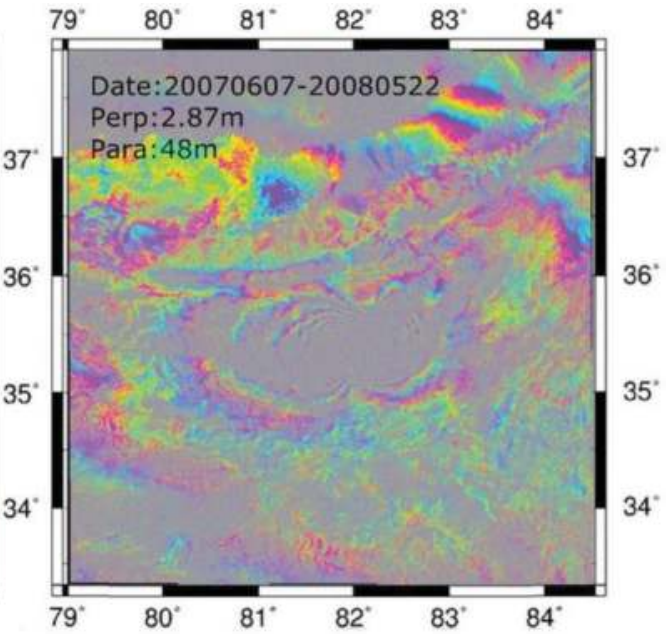

(b)

Figure 13. Other differential interferogram of Yutian earthquake (wrapped). (a) Before earthquake. (b) After earthquake. 


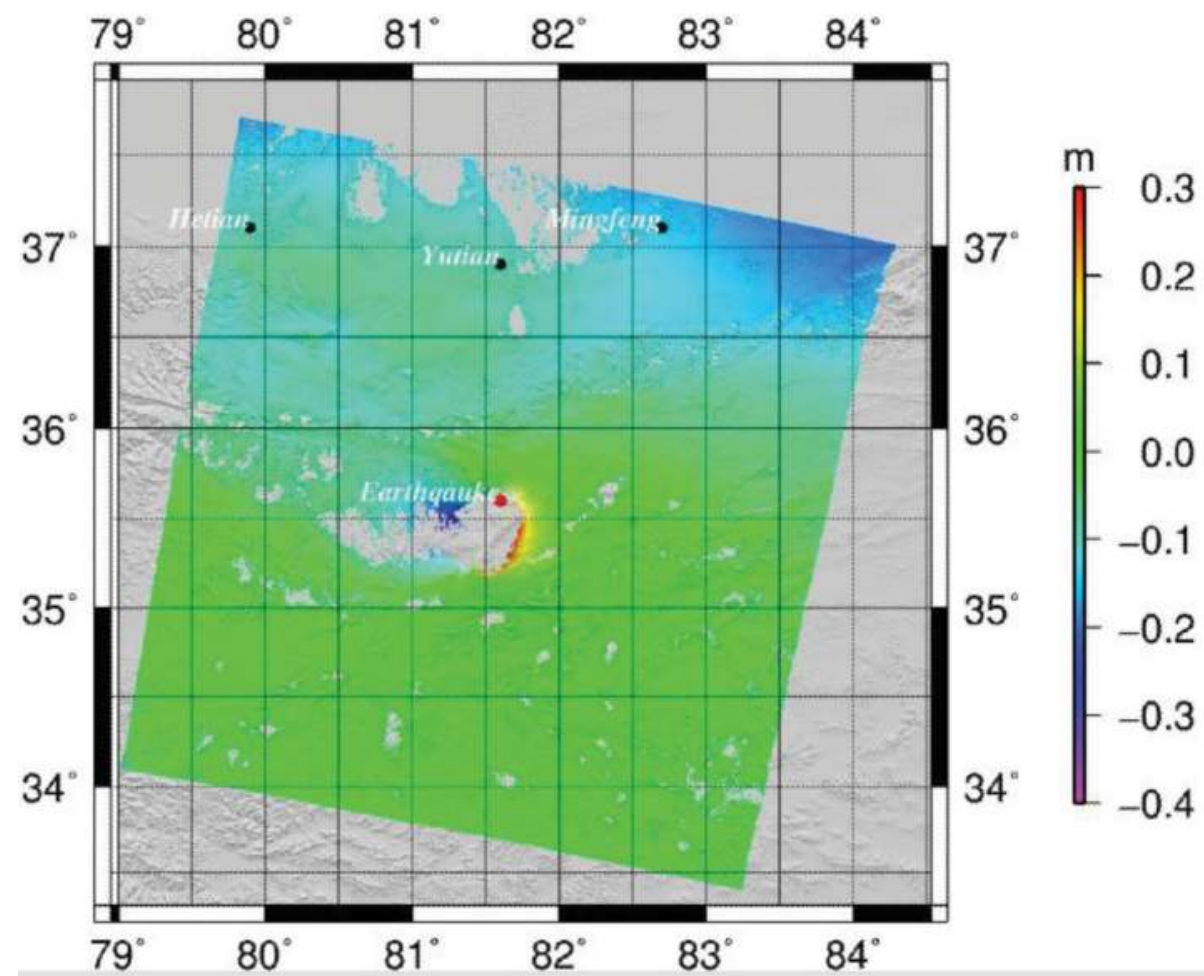

Figure 14. Wide deformation field of Yutian earthquake.

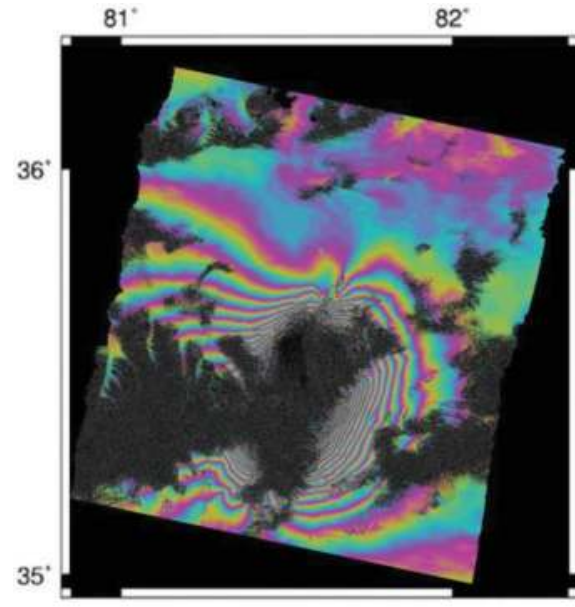

a

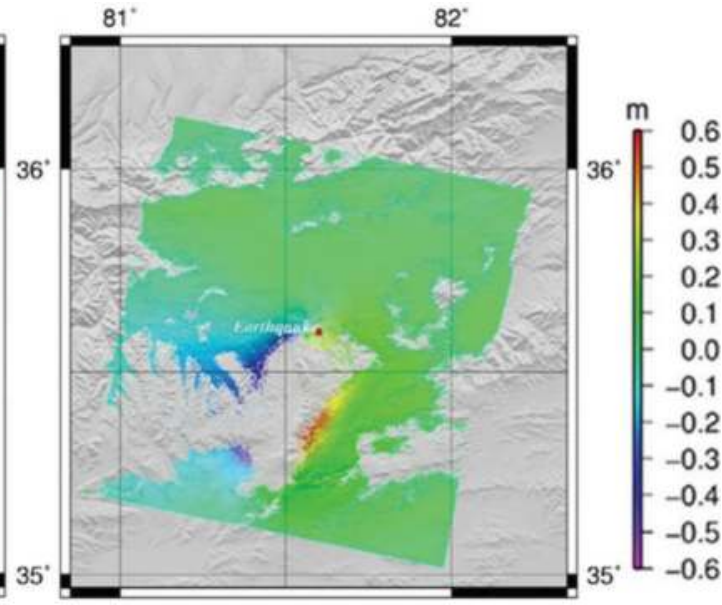

b

Figure 15. Result of IM mode for Yutian earthquake. (a) Interferogram. (b) Deformation result. 


\section{Conclusions}

In this chapter, we studied several key techniques of monitoring large area deformation caused by earthquakes. The wider deformation fields of ScanSAR interferometry data were employed to monitor the land deformation after Wenchuan earthquake (2008) and Yutian earthquake (2008), respectively, in China. The results show that in the deformation field of Yutian earthquake, the maximum deformation of hanging wall for the fault is $0.41 \mathrm{~m}$ and the maximum of the footwall deformation value is $0.32 \mathrm{~m}$. But in Wenchuan earthquake, its deformation field is greater than that of Yutian earthquake, which can preferably reflect the land deformation, especially for the deformation information of far fields. The max deformation value of the hanging wall part of the fault is $0.48 \mathrm{~m}$, while that of the foot wall part is $-0.42 \mathrm{~m}$. These results agree well with our field investigations after the two earthquakes.

The result also indicates that ScanSAR mode can fully reflect the deformation field and the corresponding seismic geological structure characteristics. Although the conventional SAR interferometry method is relatively effective because of its narrow covering area, it is very important to explore the mechanism and the dynamics of earthquakes using wider deformation fields of ScanSAR images to monitor the land deformation caused by large earthquakes such as Wenchuan 2008 and Yutian 2008 earthquakes.

\section{Acknowledgements}

Data from the European Space Agency (ESA) and the ESA Earth Observation Missions Helpdesk Team are highly appreciated. This research is jointly supported by the Natural Science Foundation of China and Jangsu province (41004003, BE2016701, SH1506, SH1608, JC1604, Z2015013), the National Key Research and Development Program of China (Project Ref. No. 2016YFB0501501), the Priority Academic Program Development of Jiangsu Higher Education Institutions, and Qing Lan Project Sponsored by Overseas Training Plan of Outstanding Young and Middle-aged Teachers of Colleges and Universities in Jiangsu Province.

\section{Conflicts of interest}

The authors declare no conflict of interest. The founding sponsors had no role in the design of the study; in the collection, analyses, or interpretation of data; in the writing of the manuscript; and in the decision to publish the results.

\section{Author contributions}

Tinhchen Jiang and Yuanzhi Zhang conceived and designed the experiments; Xiuping Wang performed the experiments; TingchenJiang, Yu Li, and Yuanzhi Zhang analyzed the data and wrote the chapter. 


\section{Author details}

Tingchen Jiang ${ }^{1}$, Xiuping Wang ${ }^{1}$, Yuanzhi Zhang ${ }^{2,3 *}$ and $\mathrm{Yu} \mathrm{Li}^{4}$

*Address all correspondence to: yuanzhizhang@hotmail.com

1 School of Surveying and Mapping, Huaihai Institute Technology, Lianyungang, China

2 Chinese Academy of Sciences, Key Lab of Lunar Science and Deep-space Exploration, Beijing, China

3 Center for Housing Innovations, Chinese University of Hong Kong, Hong Kong

4 Faculty of Information Technology, Beijing University of Technology, Beijing, China

\section{References}

[1] Cumming IG, Guo Y, Wong FH. A comparison of phase-preserving algorithms for burstmode SAR data processing. IEEE Geoscience and Remote Sensing Society'97. 1997; 2:731-733

[2] Cumming IG, Wong FH. Digital Processing of Synthetic Aperture Radar Data: Algorithms and Implemention; 2005

[3] Ferretti A, Monti-Guarnieri A, Prati C, Rocca F. InSAR Principles: Guidelines for SAR Interferometry Processing and Interpretation. Netherlands: ESA Publications; 2007

[4] Guccione P. Interferometry with ENVISAT wide swath ScanSAR data. IEEE Geoscience and Remote Sensing Letters. 2006;3(3):377-382

[5] Ortiz AB, Zebker HA. ScanSAR-to-Stripmap mode interferometry processing using ENVISAT/ASAR data. IEEE Transactions on Geoscience and Remote Sensing. 2007; 45(11):3468-3480

[6] Gudipati KV. Deformation monitoring using scanning synthetic aperture radar interferometry [PhD dissertation]. The University of Texas; 2009

[7] Johnson W. Magellan imaging radar mission to Venus. Proceedings of the IEEE. 1991; 79:777-790

[8] Lemoine FG, Kenyon et al. The development of the joint NASA GSFC and the national imagery and mapping agency (NIMA) geopotential model EGM 96. NASA no.19980218814; 1998

[9] Chang CY, Jin MY, Lou Y-L, Holt B. First SIR-C scansar results. IEEE Transactions on Geoscience and Remote Sensing. 1996;34(5):1278-1281

[10] Bamler R, Geudtner D, Schattler B, Vachon PW. RADARSAT ScanSARInterferometry. In: Proceedings of the International Geoscience and Remote Sensing Symposium, IGARSS'99. Vol. 3. 1999. pp 1517-1521 
[11] Guarnieri AM. ScanSAR interferometric monitoring using the PS technique. In: Proceedings of the ERS/ENVISAT Symposium; 2000

[12] Bamler R. Adapting precision standard SAR processors to ScanSAR. IGARSS. 1995;3: 2051-2053

[13] Guarnieri AM, Guccione P. Optimal “focusing” for low resolution ScanSAR. IEEE Transactions on GARS. 2001;39(3):479-491

[14] Guarnieri AM, Prati C. ScanSAR focusing and Intexferometry. IEEE Transactions on Geosclence and Remote Sensing. 1996;34(4):1029-1039

[15] Guarnieri AM, Rocca F. Combination of low- and high-resolution SAR images for differential interferometry. IEEE Transactions on Geoscience and Remote Sensing. 1999; 37(4):2035-2049

[16] Shen ZK, Sun JB, Zhang PZ. Slip maxima at fault junctions and rupturing of barriers during the 2008 Wenchuan earthquake. Nature Geoscience. 2009;2:717-724

[17] Xu CJ, Wang H, Jiang GY. Study on crustal deformation of Wenchuan Ms8. 0 earthquake usingwide-swath ScanSAR and MODIS. Geodesy and Geodynamics. 2011;2(2):1-6

[18] Lemoine FG, Kenyon SC, Factor JK. The development of the joint NASA GSFC and NIMA geopotential model EGM96, NASA technical paper, Nasa/TP-1998-206861; 1998

[19] Shi C, Lou Y, Zhang H, Zhao Q, Geng J, Wang R, Fang R, Liu J. Seismic deformation of the mw 8.0 Wenchuan earthquake from high-rate GPS observations. Advances in Space Research. 2010;46(2):228-235. DOI: 10.1016/j.asr.2010.03.006

[20] Burchfiel BC. A geological and geophysical context for the Wenchuan earthquake of 12 May 2008. GSA. 2008;18:4-11

[21] Hashimoto M, Enomoto M, Fukushima Y. Coseismic deformation from the 2008 Wenchuan, China, Earthquake derived from ALOS/PALSAR images. Tectonophysics. 2009, 2010; 491(1-4):59-71

[22] Wang W-M, Zhao L-F, Li J, Yao Z-X. Rupture process of the Ms 8.0 Wenchuan earthquake of Sichuan, China. Chinese Journal of Geophysics. 2008;51:1403-1410

[23] Wei M, Sandwell D, Smith-Konter B. Optimal combination of InSAR and GPS for measuring interseismic crustal deformation. Advances in Space Research. 2010;46(2):236249. DOI: $10.1016 /$ j.asr.2010.03.006

[24] Song XG, Shan X, Qu C, Zhang G, Guo L, Zhang G. Coseismic surface deformation casused by the Wenchuan M8 earthquake from InSAR data analysis. IGARSS2009, III: pp. 69-73; 2009

[25] Zhang Y, Feng WP, Xu LS, Zhou CH. Spatio-temporal rupture process of the 2008 great Wenchuan earthquake. Science in China Series D: Earth Sciences. 2009;52(2):145-154

[26] Wu L, Xiao AC, Wang LQ. EW-trending uplifts along the southern side of the central segment of the AltynTagh fault, NW China: Insight into the rising mechanism of the Altyn Mountain during the Cenozoic. Science China Earth Sciences. 2012;55:926-939. DOI: $10.1007 / \mathrm{s} 11430-012-4402-7$ 